The Journal of Animal \& Plant Sciences, 31(3): 2021, Page: 791-800

ISSN (print): 1018-7081; ISSN (online): 2309-8694

\title{
AN ECONOMIC ASSESSMENT OF MODEL FARM SERVICES CENTER IN TERMS ON FARMERS' PERFORMANCE
}

\author{
T. Shah ${ }^{* 1}$, U. Hayat ${ }^{1}$, M. Tariq ${ }^{2}$ S. B. Khan ${ }^{3}$ and L. Wang ${ }^{* 4}$ \\ ${ }^{1}$ Department of Economics and Development Studies, University of Swat-Pakistan, ${ }^{2}$ Centre for Management and \\ Commerce, University of Swat-Pakistan, ${ }^{3}$ Department of Animal Health, The University of Agriculture Peshawar \\ Pakistan, ${ }^{4}$ College of Life Science, Linyi University, Shandong 276000 P.R. China \\ *Corresponding Author's email: tariqshah@uswat.edu.pk, wanglichen@lyu.edu.cn
}

\begin{abstract}
The study aims to assess impact of MFSCs on the farming community in Khyber Pakhtunkhwa in terms of performances of two subgroups i.e. member and non-member farmers. A quantitative research design has been used with survey as strategy of inquiry conducted from 480 respondents across Swat, Mardan, DI Khan and Abbotabad districts. The study argues theoretically and indicates empirically that member respondents of MFSC were more competitive as compared to non-member farmers. In the same way the member farmers of MFSC were more prudent in terms of farm inputs usage and enjoyed higher yield across a variety of crops. The overall impact of MFSC is satisfactory, albeit room for improvement exists in areas such as by providing good variety seeds, proper fertilizer and effective utilization of combined harvesting machine. The study unveils the need to subsidize rent of agricultural machineries and prices of basic farm inputs through farmer centered policies. Further, the geographical scatterings of the MFSC keep farmers at a disadvantage which can be offset through establishment of sub-MFSC in vicinity of farmers across various districts. The study contributes to a better economic understanding of indigenous farming practices in vogue as used by autonomous and registered-member of MFSCs in local context.
\end{abstract}

Keywords: Economic assessment, Farming community, Model Farm Services Center, Farm inputs, Yield difference.

https://doi.org/10.36899/JAPS.2021.3.0269

Published online November 09, 2020

\section{INTRODUCTION}

Agriculture is an important sector of Pakistan and contributes $19.9 \%$ to national GDP and serve as livelihood source for $42.3 \%$ of population (GOP, 2018). The agriculture sector is confronted with numerous challenges such as production, consumption and export targets as compared with developed countries (Rathakrishnan and Mahmood, 2019). This assertion goes in conformance with a significant yield differences about $53-82 \%$ as observed by (Kamal, et al., 2012). Partly, the spells of climatic variability also reduce yield for some of the main crops such as wheat, rice and maize (Sajjad, et al., 2020). Besides this, other reasons for lower productivity include but are not limited to poor land management practices, lack of proper capital, outdated technology in vogue and inadequate dissemination of scientific information at grassroots levels which makes farmer vulnerable to seasonal shocks. However, the most pressing issue, confronting farmers is lack of farm critical information which can substantially boost agricultural productivity (ICSAG, 2005).

Pakistan like many other of its contemporaries depends broadly on agriculture as majority of communities are living in rural areas. Most of the people in farming fraternity are diligent in the performance of agriculture related endeavors, despite lower levels of productivity. Land of the country is fertile and the climatic condition of the region is suitable for the production of several crops. Most common crops grown in the country include wheat, rice, cotton, sugarcane, fruits and vegetables (Abdul Rehman, et al., 2015). The farmers are also industrious in the country, but despite this, production yield is not commensurate with their efforts due to the fact that production per unit land is dismal when compared with global averages. The dismal performance of farmers can be improved with the adoption of new scientific mechanisms of farming ranging from introduction of latest technology to use of better quality of seeds which are insects resistant in tandem with improvements in indigenous farm practices, better irrigation and plant protection interventions.

For improving overall farm productivity, there is a dire need of full-fledged endowment of agricultural research as well extension work to abate the existing gaps and dichotomies in terms of productivity. In domains of agriculture a proportionate relationship exists between growths with rise and stability of the farming community through use of farm advisory services (Ashraf, et al., 2019). In the same vein, (Budak, et al., 2010) asserts that there exists a dire need to raise the number of agriculture oriented extension services for farmers. It has been observed that extension services increases crop yield which inwardly improves socio-economic indicators of 
farmers' community (Mirrani and Memon, 2011). Similarly, finding of (Baloch and Thapa, 2018); (Shah, et al., 2016); (Shah, et al., 2019) pointed that farmers are more productive, if they have access to extension services and their yield is higher than those farmers who lack access to value laden services of MFSCs.

A variety of extension based approaches were introduced in developed world which had made agriculture extension within reach of farmers although greater productivity has inverse relationship with farming occupation as only three percent of population in United States out produce the rest of world. In Pakistan there has been a gradual rise of awareness of farm advisory services, despite all evidence to the contrary in terms of their effectiveness when compared with developed world. In fact, more than half of the global food security is contributed by farmers in rural areas, thus making rural farmers a preferred recipient of farm advisory service (IFAD, 2012). In spite of their relevance and importance to global food security farmers in rural areas are exposed to exogenic shocks in the form of lower economic returns, depletion of natural resources and dearth of access to knowledge base and markets (Lipton, 2005). In this context, the extension agents and provision of services to farmers can potentially serve as a bridge between knowledge creators and user i.e, farmers (Ahmad, et al., 2007). This goes without saying that even extension agents of various programs confront a multiplicity of challenges which include design of appropriate extension programs which transfers technological advancements in a manner that keep grass roots level farmers interested with value laden and market driven results (David, 2007).

It is well recognized globally that when public sector works in tandem with private in the form of partnership, the results are more efficient and responsive to needs of farmers. Moreover, it has been observed in the past few years, that majority of low-tech innovation have been developed by indigenous farmers as a response to changing natural environment as against those dedicated to this job in various state sponsored research centers. In the same vein, farm advisory services should focus on most pressing and need specific issues of farmers. Thus, it calls for a sound integration among three main pillars of the agricultural sector: innovative researchers, extension agents, and farming communities for consequential agricultural plans in different part of the world regarding desire production and uplifting the socio economic condition of the farmers (Ashraf, et al., 2019). The extant scholarly literature reveals major problems in domains of extension systems which include bureaucratic topic-down approaches, poor linkages between research and extension and gradual decline in income of farmers which adversely impacts their empowerment (Singh, et al., 2006). (Lemma and Tesfaye, 2016) highlighted that flaws in proper management and implementation of mutually beneficial policies, coupled with improper institutional conditions are leading constrains that prevent the linkages in agricultural system. (Birner and Anderson, 2007) asserts that extension initiatives are marred by the fact that they are cash and man strapped coupled with considerably low level of farmer participation and scarcity of funds for fields' staff with higher turnover rate and job hopping. Introducing improved technology or up gradation as well as introduction of public-private partnership in the existing practices can enhance the overall agricultural productivity in Pakistan (Rehman, et al., 2012; Aslam, 2016).

In Pakistan the Government in Khyber Pakhtunkhwa (KP) has initiated extension program for welfare of farmers through public-private partnership by the name of model farm service center (MFSC). The purpose of MFSC is to serve as a launching pad for resolving issues of farming community through creation of linkages with Government agencies. The MFSC registers local farmers who are facilitated by professionals as a general body of MFSC. The focus of MFSC has been to cater the needs of registered farmers through identification of gaps in existing farming practices and offering solutions in the form of best practices, policy inputs and solutions. MFSC offers a variety of trainings for farmers in domains cropping systems in order to make them more sustainable and value-laden. The main purpose of this study is to examine various activities undertaken by extension services of MFSC in comparison to farming modalities in vogue. Based on preceding discussion in the light of interventions afforded by MFSC we hypothesize that yield of famers registered with MFSC is higher when compared to those autonomous farmers who are yet to register. Other than this, the study also endeavors to explore role and relevance of extension programs in regards to transfer of technology (upfront) in farming fraternity of the target area under study.

\section{MATERIALS AND METHODS}

The study use a positivist ontological world view which emphasizes empirical data collected through survey in the form of strategy of inquiry in objective manner (Yousafzai, et al., 2020). In line with our ontological stance a deductive approach is used as per need of the study by using questionnaire developed specifically (Iqbal, et al., 2018). The current study is conducted in four districts of North western province of Pakistan namely Swat, DI Khan, Abbotabad and Mardan using a purposive sampling technique. The study espouses a pragmatic research approach with the use of both primary and secondary data to achieve the purpose of research. Overall, from above four districts, representative samples of 120 respondents were selected, which makes 480 respondents in total across four districts of Khyber Pakhtunkhwa. A detailed questionnaire was 
made in reference to extant literature and personal observation to elicit pertinent information from respondents. The respondents were given pseudonyms to allow them confidence and assurance in order to conceal their identity.

Moreover, part of the data collected from registered members of MFSC was empirical in nature. Therefore SPSS was incorporated for data analysis and entry. More specifically descriptive statistics i.e., cross tabulation and frequencies were incorporated in analysis through SPSS. Furthermore, in order to test the central hypothesis i.e., "the yield of registered members of MFSC is higher than those of autonomously operating farmers" wheat and maize crops were analyzed via independent- sample T-tests. A similar treatment was extended to other variables such as milk extracted from livestock for both types of respondents. Furthermore, dummy variable regression model was incorporated to assess disparity in yield among registered and nonregistered participants across 04 categories of crops and milk from livestock.

$$
y_{i}=\alpha_{0}+\alpha_{1} D .+\varepsilon
$$

$\boldsymbol{y}_{\boldsymbol{i}}=$ The output or yield extracted from crops or live stock

$\alpha_{0}=$ Invariable Constant

$\alpha_{1}=$. Coefficient

$\mathbf{D}=$ one when participant is registered with MFSC and zero otherwise

$\varepsilon=r \quad e$

\section{RESULTS AND DISCUSSION}

The empirical evidence selected from registered and non-registered members of MFSC were analyzed and furnished in following order. As evident from Table No 1 the general features (biographic characteristics) of registered and non-registered participants and their associated variations in terms of mean were identified using t-statistics at 95 percent confidence level indicating significance. The average age of registered participants is 45.43 while for non-registered participants was 45 years having a mean difference equivalent to 0.43 . As evident from associated p-value of 0.71 there exist nonsignificant variations among age in years of both registered and non-registered participants. In the same vein, educational level of participants represent years of formal schooling. The result below indicates that nonregistered members had 6.03 years of schooling in comparison to 8.61 years for those registered with MFSC. The mean difference of both categories of participants stood at -2.58 years with t-statistic showing significant variation among educational levels of participants of the study.

The empirical data collected indicate that both set of participants had more than twenty years of farming experience. In this study an overwhelming majority of participants hailed from joint-family system. The tstatistics indicate a significant variation in terms of their family types of both groups of participants. On one hand, the total average number of non-registered farmers stood at 10.56. On the other hand, registered members were 12.87 which gave -1.23 as mean difference. In case of former group the total number of family members engaged in agriculture was 1.99. While, in case of later group it was approximately 2.18 having -0.19 as mean difference and corresponding t-statistic of 0.08 . The results as indicated by t-statistics reveal existence of significance across family members of both groups of participants. The non-registered participants on average hired the services of 3.97 laborers which is comparatively less than those employed by registered participants with overall mean difference at -2.46 and 0 values for tstatistic. The income generated from farming in case of non-registered participants stood at 192538 Pakistani rupees which is comparatively less than 575408.74 rupees of registered members with average mean difference of -381870 with -1.71 as t-statistic value. A resultant p-value of 0.09 indicates existence of nonsignificant differences in terms of on farm income generated for both set of participants.

Table 01 Biographic characteristic of participants.

\begin{tabular}{lcccc}
\hline Characteristics & Non-members & Members & $\begin{array}{l}\text { Mean } \\
\text { diff. }\end{array}$ & p-value \\
\hline Age of the participants & 45.43 & 45 & 0.43 & 0.71 \\
Education of. Participants & 6.03 & 8.61 & -2.58 & 0 \\
Farming experience & 22.23 & 21.35 & 0.88 & 0.46 \\
Joint family or separate & 1.66 & 1.74 & -0.08 & 0.05 \\
Family members number & 10.56 & 12.87 & -1.23 & 0 \\
Numbers involved. in farming & 1.99 & 2.18 & -0.19 & 0.08 \\
Casual Labor. involved in Farming & 3.97 & 6.43 & -2.46 & 0 \\
On Farm Income/Year (Rs.) & 193538.46 & 575408.74 & -381870 & 0.09 \\
\hline
\end{tabular}

A number of scholarly studies have been undertaken to assess the role of irrigation in relation to livelihoods of farmers. The finding of (Smith, 2004); (Akpabio, et al., 2007) and (Fatemeh, et al., 2009) 
reveals that with proper irrigation, the yield of many crops can be increased Similarly (Xie, et al., 2014) identified irrigation as a source of improving mechanism for agricultural productivity. In advanced farming systems, the dependency of crop yield solely limited to per unit of land (traditional perception) is replacing with a new paradigm which largely depends on water availability (Rahaman, et al., 2007). According to (Dhanda, et al., 2004) lower levels of water provision affect crop growth across various stages. The table 2 offers information in regards to land utilization of both groups of respondents. The $p$-value generated from analysis of both sets of participants (irrigated and rainfed land) indicates significant differences as shown below.

Table 02 Irrigation and land utilization of participants.

\begin{tabular}{|c|c|c|c|c|}
\hline \multirow{2}{*}{ Land utilization } & Non-members & Members & \multirow{2}{*}{ Mean diff. } & \multirow{2}{*}{ p-value } \\
\hline & \multicolumn{2}{|c|}{ Area in acres } & & \\
\hline Irrigable farmland (rented) & 8.47 & 10.21 & -1.75 & 0.55 \\
\hline Arid Farmland (rented) & 0.69 & 5.25 & -4.56 & 0.20 \\
\hline Communal irrigable farmland & 6.74 & 15.25 & -8.51 & 0.04 \\
\hline Communal arid farm land & 2.19 & 1.5 & 0.69 & 0.45 \\
\hline Irrigable cooperative farmland (shared) & 29.31 & 15.58 & 13.74 & 0.27 \\
\hline Operational irrigable farmland held by farmers & 13.92 & 19.71 & -5.79 & 0.20 \\
\hline Operational arid farm land held farmers & 2.78 & 4.34 & -1.56 & 0.00 \\
\hline
\end{tabular}

Domesticating livestock is one of the ancient achievements of mankind. This sector contributes 60.5 percent of total agriculture value produced, and accounts for 11.2 percent of GDP of Pakistan (GOP, 2019). In terms of the number of buffaloes, goats and cattle, Pakistan holds $2^{\text {nd }}, 3^{\text {rd }}$ and $9^{\text {th }}$ position respectively in the world. It ranks 4th in terms of milk production in the world (Ashfaq, et al., 2020). The population of all aggregate cattle (including cows) is higher than buffalos in Pakistan but contribution of buffalo is more than cow in terms of milk production (GOP, 2018). According to (Vries, 2008) animal farming offers alternative livelihoods mechanisms for farmers across the world as they both enjoy a symbiotic relationship as without cultivated plants and livestock existence of human life is beyond fathoming. The common livestock raised by farmers in Khyber Pakhtunkhwa province are cows, goats/sheep's, buffalos and poultry.

The ensuing table 03 indicates milk production extracted from livestock of both registered and nonregistered members of MFSC. The self-explanatory pvalues show level of significance in terms of differences in yield of milk. The data reveals that registered members obtain relatively high milk levels from goats, buffaloes and sheep The empirical evidence suggests that cow milk in terms of yield for non-registered members is higher than that of registered members.

Table 03 Participants responses in regards to livestock associated yield.

\begin{tabular}{|c|c|c|c|c|c|c|c|c|}
\hline \multicolumn{5}{|c|}{ No } & \multicolumn{4}{|c|}{ Milk production } \\
\hline livestock & Non-members & Members & Mean diff & p-value & Non-members & MFSC Members & Mean diff & p-value \\
\hline Goats & 3.32 & 3.77 & -0.45 & 0.60 & 1.75 & 2.19 & 0.17 & 0.34 \\
\hline Buffaloes & 2.94 & 2.99 & -0.05 & 0.89 & 7.70 & 7.98 & -0.28 & 0.49 \\
\hline Cows & 3.08 & 2.99 & 0.09 & 0.72 & 5.80 & 6.75 & -0.95 & 0.03 \\
\hline Sheep & 2.50 & 5.40 & -2.90 & 0.31 & & 0.67 & & \\
\hline Poultry & 1065.82 & 9.59 & 1056.24 & 0.09 & & & & \\
\hline
\end{tabular}

Having discussed issues pertaining to livestock and their associated yield in terms of milk, now we pay attention to a major crop of wheat grown across Pakistan. Wheat is used as staple and it is now wonder that this crop is also reckoned as a cash crop in Pakistan and elsewhere. Globally, around $36 \%$ of population used wheat as a staple food that contains carbohydrates, protein and vital minerals such as Zinc, Phosphorus, Copper, Magnesium and Iron. Most of the farmers grow wheat because of its higher production likelihood than other crops and also known as king of cereals (Din, et al.,
2020). Top wheat producing countries are China, India, Russia, USA, France, Canada, Germany and Pakistan. Due to exponential growth in population there has been a corresponding rise in consumption of wheat in Pakistan. The wheat production requires attention in terms of investment in technology, better variety of seeds as well as identification of proper and suitable time for both irrigated in rainfed lands. The table 04 below depicts information regarding wheat production in Pakistan. It has been established from empirical evidence collected that seed sowing rate among non-registered members of 
MFSC is lower than their counterparts in the range of mean difference of -0.45 . On one hand, the wheat seeds sown are changed after duration of 2.05 years for nonregistered members. On the other hand, their counterparts change it after duration of 1.83 years with a mean difference equivalent to 0.23 Other than this, the tstatistic of 0.14 indicates variations across replacement of seeds (wheat) for participants. The non-registered farmers consume on average 0.76 pouches of $\mathrm{Di}$ Ammonium Phosphate (DAP) in contrast to registered members who consume a higher 0.83 pouches for one acre of land with mean difference equivalent to -0.07 . The results of $t-$ statistic at 0.10 indicate a non-significant level of difference in regards to quantity of DAP consumption for wheat growers. The quantity of Single super phosphate consumption by non-registered members stands at 1.44 per acre; while, that of their counterparts is 2.2 pouches per acre with average mean variation of -0.7 pouches.
In terms of t-statistics value of 0.02 infers that there exists a significant level of variation in the quantity of three fertilizers used by both groups of participants in wheat crop cultivation. The quantity of urea used by nonregistered participants is 1.37 pouches, while for their counterparts registered with MFSC it is slightly higher at 1.43 pouches per acre with average mean difference of 0.06 . The resulting $\mathrm{t}$-statistic indicate a non-significant variation in terms of quantity of urea consumed per acre of wheat crop in selected districts of KP, Pakistan. The results indicate that wheat production of MFSC registered participants were 25.23 mounds, while that of nonregistered farmers stood at 24.14 mound per acre, denoting average mean difference of -1.09 . But in this case, the t-statistic of 0.27 indicates a non-significant variation in terms of wheat yield of both groups of participants.

Table 04 Participants responses in regards to wheat.

\begin{tabular}{lcccc}
\hline Wheat & Non-Member & Member & Mean diff & p-value \\
\hline Wheat seed rate consumed/ in (Kg)/acre & 48.84 & 49.29 & -0.45 & 0.63 \\
Seed replacement for wheat & 2.05 & 1.83 & 0.23 & 0.14 \\
DAP pouches consumed for wheat crop/acre (No.) & 0.76 & 0.83 & -0.07 & 0.10 \\
Other fertilizers pouches consumed for wheat crop/acre & 1.44 & 2.2 & -0.76 & 0.02 \\
Number of Urea bags used/ acre & 1.37 & 1.43 & -0.06 & 0.54 \\
Wheat production/ acre in mounds & 24.14 & 25.23 & -1.09 & 0.27 \\
\hline
\end{tabular}

(1 mound=40Kgs)

After discussing wheat, the authors now draw attention towards the maize crop grown across Pakistan in both irrigated and rainfed lands. Maize is third important crop after wheat and rice and accounted for $0.5 \%$ to national GDP and contributes 2.7 percent to the value addition in agriculture (Sattar, et al., 2017). In KP province, it was grown on about (471) thousand hectares with a production of (915) thousand tons annually. The average yield of maize in KP was (1943) kg/ha (Binder, et al., 2008). Among the various crops in Pakistan, yield of wheat and maize crops indicates positive growth at the rate of $0.5 \%$ and $6.9 \%$, respectively (GOP, 2019). In addition to catering the demands of both human and animals in the form of green fodder and grains respectively, maize is also consumed as a staple in daily diet. In the table 05 we display data pertaining to maize crop cultivated by participants of study. The empirical evidence generated unveils that non-registered member of MFSC use hybrid maize seeds at the rate of 8.01 kilograms per acre of land, while their counterparts consume 8.49 kilograms per acre with overall average mean difference of -0.48 . The $t$-statistic of 0.18 indicates a non-significant variation in terms of seed rate across the two categories of respondents. The former group changes the maize seeds after duration of 0.19 years, while the latter changes seeds of maize after duration of 2.09 years showing average mean difference of 0.09 . The 0.67 result of t-statistics again indicate a non-significant difference in terms of replacing hybrid maize wheat. The quantity of DAP consumption of registered members of MFSC is 1.05 pouches having average mean difference of 0.24 . The results of t-statistics of 0.01 indicate a significant variation in quantity of DAP pouches consumed per acre of hybrid maize. The quantity of urea consume by nonregistered MFSC participants is 1.57 pouches per acre of land, while that of their other counterparts stand at 1.88 pouches for hybrid maize with average mean difference of -3.0 The resultant t-statistics of 0.10 indicates a nonsignificant variation in terms of quantity of urea consumed per acre in regards to cultivation of hybrid maize crop. The non-registered MFSC participants consume slightly greater quantities of other fertilizers at two bags per acre of land, while those registered MFSC farmers consume 1.17 pouches denoting average mean difference of 0.83 . The 0.01 result of t-statistics indicate a significant difference in terms of quantity of other fertilizers consumed in per acre land for cultivation of hybrid maize. The overall, yield in terms of maize (hybrid) is greater for registered members at 32.25 mounds per acre than non-registered farmers with average mean difference of -5.27 . The 0.04 result of t-statistics indicate a significant variation in terms of production of maize (hybrid) crop cultivated by participants of study. 
Table 05 Participant responses in regards to maize.

\begin{tabular}{lcccc}
\hline Maize crop & Non Member & Member & Mean diff & p-value \\
\hline Hybrid maize seed rate consumed/acre in kgs & 8.01 & 8.49 & -0.48 & 0.19 \\
Replacement of seeds for maize & 2.19 & 2.10 & 0.09 & 0.67 \\
DAP pouch used for hybrid/acre & 0.81 & 1.05 & -0.24 & 0.01 \\
Other fertilizers consumed for hybrid/ acre & 2 & 1.17 & 0.83 & 0.01 \\
Urea pouch used for hybrid /acre & 1.57 & 1.88 & -0.30 & 0.10 \\
Hybrid maize yield per acre (mounds) & 26.98 & 32.25 & -5.27 & 0.04 \\
\hline
\end{tabular}

( 1 mound $=40 \mathrm{Kgs})$.

In Pakistani About 80 percent farmers are small land holders and their limited ability to purchase maize hybrid seeds is one of the primary reasons for the poor adoption of hybrid seeds (Akhter, et al., 2020). It is well established the world over that quality input is needed for quality outputs and same is the case in terms of seeds in domains of crop cultivation and agriculture The main outlets for procurement of seeds are MFSC, extension departments, NGOs and at times farmers also retain some of their produce to be later used as seeds. The provision of quality seeds at reasonable price increases the likelihood that a better harvest can be made. The figure 01 indicates the existing sources from where the registered and non-registered members of MFSC can procure seeds for their personal farm consumption. The empirical evidence collected suggests that an overwhelming majority of participants use their own seeds for cultivation of various crops. Occasionally, they also resort to purchase from fellow farmers and at times from dealers of agriculture products; but still others procure seeds from MFSC, NGOs and other agriculture extension related departments operating in their vicinity

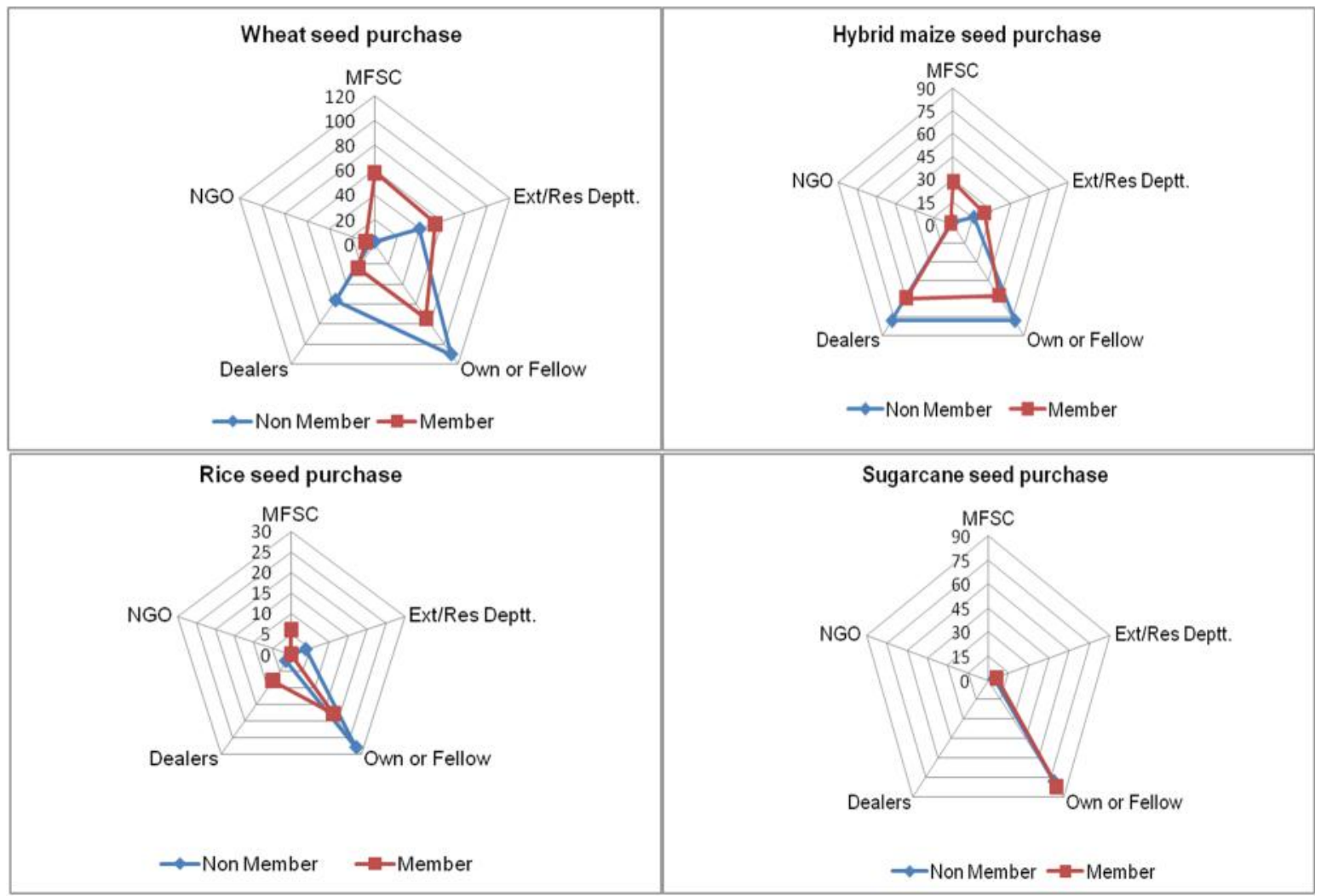

Figure 01Frequency distribution of participant's procurement of seeds.

Every extension program has both pros and cons. The figure 02 reveals some of the pressing issues confronted by participants of study in regards to MFSC. An overwhelming majority of participants (44) reckon that there were literally no or little facilities available to them. While, another (28) asserts that price of inputs provided by MFSC were non-competitive in comparison to market rates. Still another (50) respondents lamented 
unavailability of input on desired time of cultivation season. Some other participants (32) highlighted that MFSC are located at a large distance from their villages with inadequate staff who are unavailable most of the time during duty hours. In addition to this, almost (08) participants proclaimed that technology available at various MFSC centers is old fashioned and not workable. Moreover, they lamented they low quality of fertilizer as compared to open market. While still others (34) respondents asserted that attitude of MFSC personnel is unbecoming of a facilitator as they exercised nepotism and favoritism on important occasions. Almost (20) participants lamented the fact that MFSC workers do not observe office hours and also reported adulteration of seeds which serves as a root cause for lower productivity. In addition to this, (12) participants apprised the enumerators regarding the dire need to further strengthen the MFSC centers by creation of credit facilities for farmers as well as provision of laser machines. Overall (64) participants complained regarding lack of machinery, seeds and quality fertilizer on suitable time of the year at MFSC.

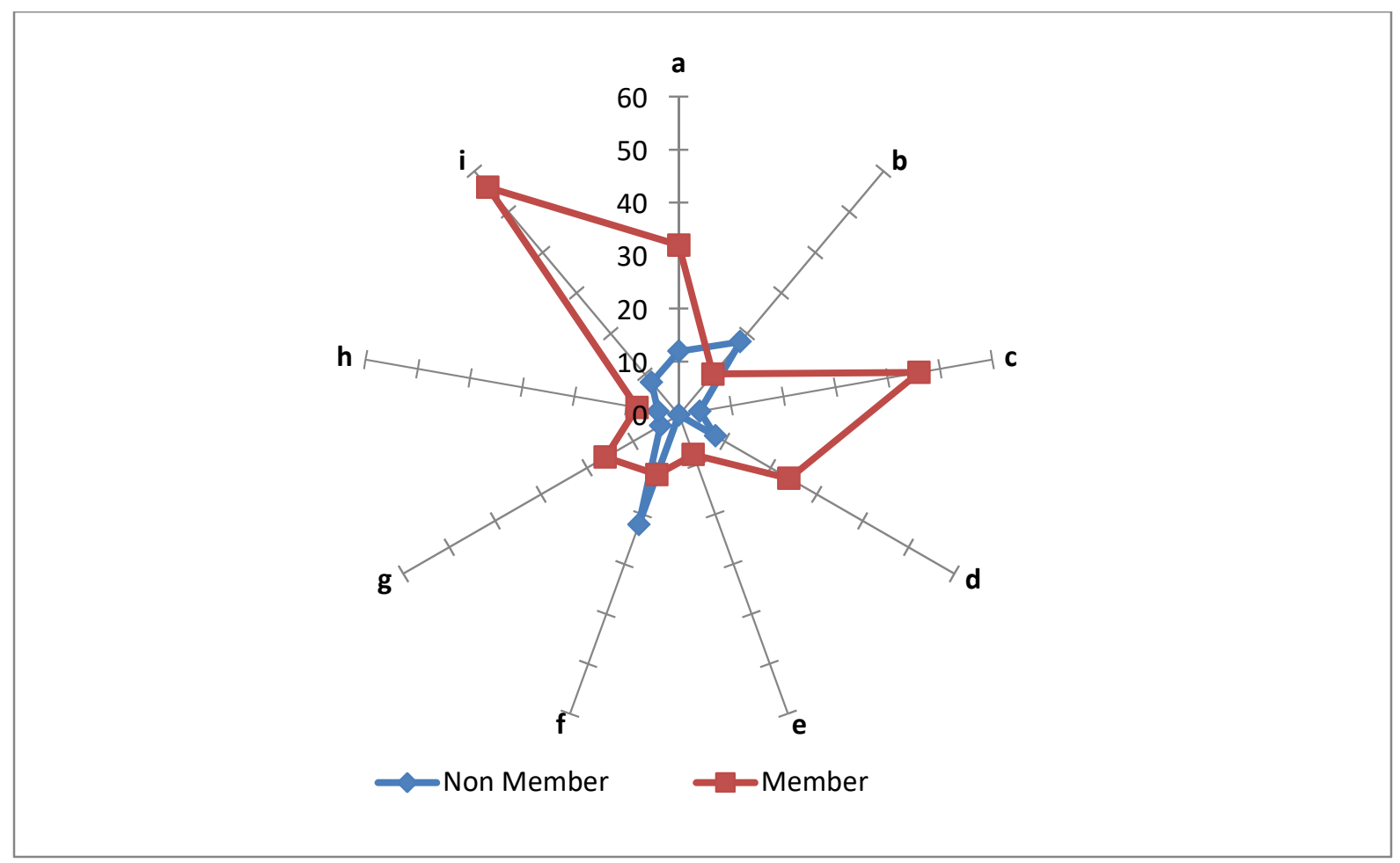

Figure 02 Problems of participants in regards to MFSC

${ }^{\text {a }}$ lack of basic farm inputs

${ }^{\mathrm{b}}$ high rate of available farm inputs

${ }^{c}$ unavailability of basic farm tools and apparatus on time

${ }^{d}$ faraway geographical location, shortage of staff .and inputs and absence .from office

${ }^{\mathrm{e}}$ agric equipment and fertilizer in low grade quality

${ }^{\mathrm{f}}$ lack of judicious distribution of farm inputs and vicinity of MFSC.

${ }^{g}$ MFSC staff performing duties below par in terms of availability during working hours, adulteration and distribution of basic farming amenities

${ }^{\mathrm{h}}$ poor performance in terms of credit advancement, tools and agric machineries

${ }^{\mathrm{I}}$ lack of on time provision of farming machineries and salient inputs.

All participants were requested for their feedback in regards to improvement of service of MFSC. The figure below indicates that mostly (40) respondents show that availability of farm inputs is a basic requirement of farmers. Similarly, (18) participants asserted that there is need to arrange training for framers and argued for creation of sub MFSCs at Union council
(UC) levels. Other than this, (24) participants argued in favor of provision of combine harvesting machine through MFSC platform Most of the respondents about (40) in number, expressed their concern over unavailability of basic farm inputs and machinery to farmers in order to improve the performance of MFSC. Still others (08) participants were grieved over the 
discriminatory distribution of farm inputs which does not go in sync with the spirit for which MFSC were established. Almost (10) participants reckoned that basic inputs such as seeds, machinery and established of MFSC offshoots were need of the day. A few others, (06) participants suggested the provision of revolving funds through MFSC during crop seasons to improve overall performance of all stakeholders related to MFSC. Finally, some (22) remaining participants of study advocated for provision of better seeds, fertilizers and associated farm inputs on subsidized rates as Pakistan is agro-based economy.

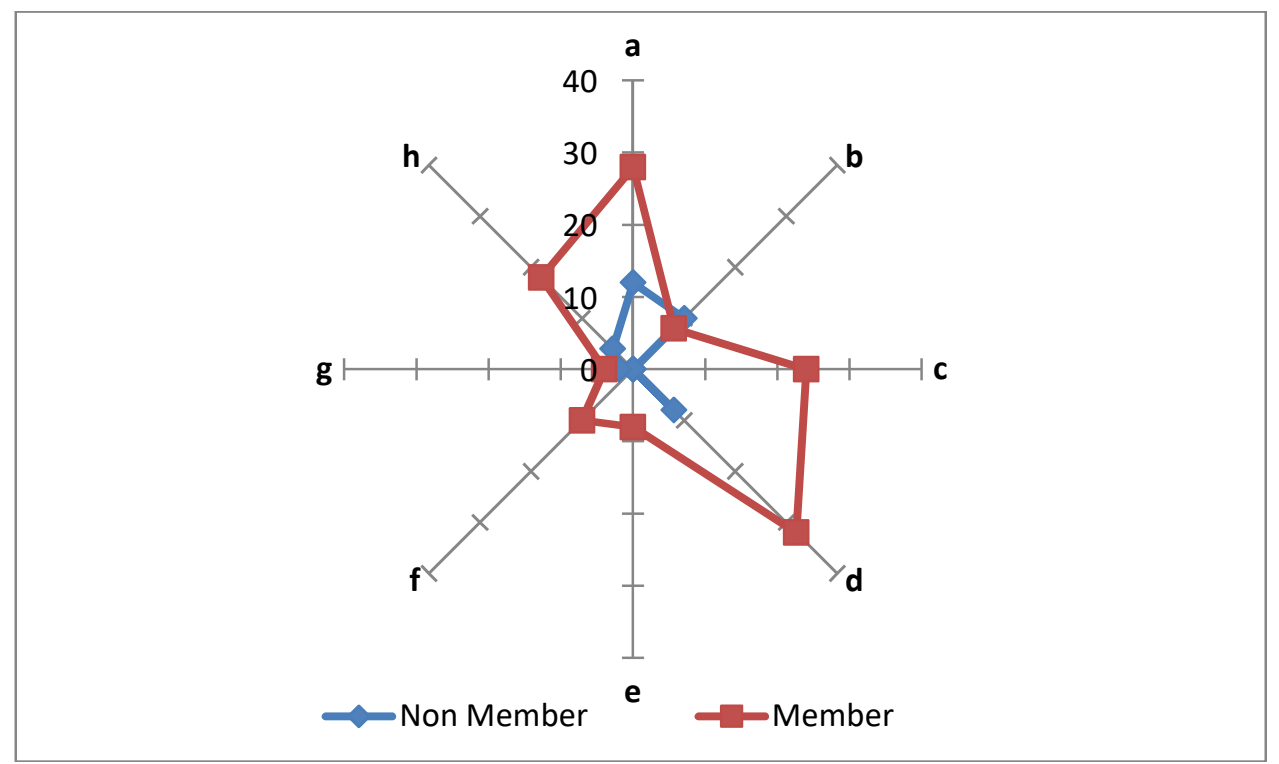

Figure 03 Suggestion of participants regarding MFSC improvement

${ }^{a}$ provide basic farm inputs

${ }^{\mathrm{b}}$ provide Training and offshoots MFSC establishment

${ }^{c}$ provision of combined harvesting machine

${ }^{d}$ timely availability of inputs or machinery

${ }^{\mathrm{e}}$ discourage discriminatory and timely availability of farm inputs

${ }^{\mathrm{f}}$ provision of basic farm inputs along with agric-machinery and offshoots MFSC establishment

${ }^{\mathrm{g}}$ provision of funds facilities and required inputs on credit

${ }^{\mathrm{h}}$ accessibility of farm inputs/agric-machinery on subsided ratio properly

Conclusion and policy implication: This study was carried out to assess the economic impact of advisory service centers established for farmers across four districts of KP Province to assess prevalent farming practices. For this, an effort was made to attain an epic understanding the existing farming patterns of the both member as non-member of MFSCs in terms of general information, land utilization, crops yield and livestock production. To summarize, in this study we found that most of the farmers were middle aged with low levels of education. It has been observed that most of participants use their personal seeds for sowing and alternately purchases it from fellow farmers in times of need. Considerably, higher yields were observed in hybrid maize and rice per acre by member farmers of MFSC. Similarly, it was observed that a vast majority of respondents' possess greater farming experience, yet the cow milk yield of the member farmers of MFSC were significantly higher than non-member farmers. Although it was observed that MFSC has an encouraging impact on the farming communities as evident from significant rise in member farmers' productivity. Yet, several limitations such as unavailability of basic farm inputs in MFSC on proper time, inappropriate prices and unbecoming attitude of the some personnel were also reported by most of the respondents. In the light of empirical analysis for study in order to make these MFSC more productive, these few recommendations are made.

Increase the number of registered farmers of MFSC at grassroots level. In order to make them more productive, progressive provision of advisory services along with advanced machinery and inputs for both registered and non-registered members at doorstep is necessary. Similarly, considerable subsidy on prices of farm inputs and rent of machineries to farming communities will make these MFSCs more desirable. Furthermore, judicious distribution of farm inputs among farming community and availability of credit and farm 
inputs to farmers is essential to enhance their overall productivity. There is also a dire need to extend MFSCs to remote areas to improve access of MFSCs services to poor farmers in order to germinate a spirit of advancement through use of innovative farming practices.

The current research has been delimited across a limited number of crops and livestock yield in four districts of KP. Further, studies are needed to enhance external validity of findings across the entire 34 operational units in various districts of MFSCs in Khyber Pakhtunkhwa, Pakistan. Moreover, the current study espoused a quantitative approach to achieve the purpose of study. Using this study as stepping stone, qualitative and mixed methods researches would further improve our understanding of efficacy of MFSCs services.

\section{REFERENCES}

Abdul, R., J. Luan, S. Babar, A.C. Abbas, H. Imran, N. Ghulam and S.I. Muhammad (2015). Economic perspectives of major field crops of Pakistan: An empirical study. Pacific Sci. Review B: Humanities and Social Sci. (1): 145-158.

Aslam, M. (2016). Agricultural productivity current scenario, constraints and future prospects in Pakistan. Sarhad. J Agric. 32(4): 289-303.

Ahmad, S., M. Jamal and A. Ikramullah (2007). Role of extension services on the farm productivity of district Swat. Sarhad J. Agric. 23(4): 1265-1271.

Ashraf, S., Z. Y. Hassan and I. Ashraf (2019). Dynamics of agricultural extension services in Pakistan: A history of national performance, The J. Anim. Plant Sci. 29(6): 1707-1717.

Akhter, A., A. R. B. Issa, and D.B. Rahut (2020). Adoption and Impact of the Maize Hybrid on the Livelihood of the Maize Growers: Some Policy Insights from Pakistan, Scientifica. (2020): 1-8.

Akpabio, E. A., N.M. Watson, U.E. Ire and I. E. Ukpong (2007). Integrated Water Resources Management in the Cross River Basin, Nigeria. Int. J. Water Resour. Dev. 23(4): 691-708.

Ashfaq, M., R. Kousar, M.S.A. Makhdum, S. A. A. Naqivi and A. Razzaq (2020). Farmers' perception and awareness regarding constraints and strategies to control livestock diseases Pakistan J. Agri. Sci. 57(2): 573-583.

Baloch, M.A. and G.B. Thapa (2018). The effect of agricultural extension services: Date farmers' case in Balochistan, Pakistan. J. Saudi Soc. Agric. Sci. 17(3): 282-289.

Binder, J., S. Graeff, J. Link, .W. Claupein, M. Liu, M. Dai and P. Wang (2008). Model based approach to quantify production potentials of summer maize and spring maize in the North China Plains. Agron. J. (100): 862-873.
Birner, R. and J.R. Anderson (2007). How to make agricultural extension demand-driven? The case of India's agricultural. Extension policy. Discussion Paper 00729. Washington D.C. IFPRI Intl. Food. Policy Res Inst.

Budak, D.B., F. Budak and Ö.Ö. Kaçira (2010). Livestock Producers. Needs and Willingness to Pay for Extension Services in Adana Province of Turkey. Afric. J. Agric. Res. (5): 1187-1190.

David, S. (2007). Learning to think for ourselves: knowledge improvement and social benefits among farmer field school participants in Cameroon. Int. Agri. Ext. Edu. 14(2): 35-49.

Din, K., N.U. Khan, S. Gul, S.U. Khan, I. Tahir, Z. Bibi, S. Ali, S.A. Khan, N. Ali, I.A. Khalil and O. Mumtaz (2020). Combining ability effects and inheritance of maturity and yield associated traits in F2 populations of Wheat, The J. Anim. Plant Sci. 30(4): 988-1003.

Dhanda, S.S., G.S. Sethi and R. K. Behl, 2004. Indices of drought tolerance in wheat genotypes at early stages of plant growth. J. Agron. Crop Sci, 190(1) 6-12.

Fatemeh P., I. Malekmohammadi, M. Chizari, Jamal and M.V.Samani (2009). The Role of Optimizing Agricultural Water Resource Management to livelihood Poverty abolition in Rural Iran, (AJBAS) Aust. J. Basic and Appl. Sci. 3(4):38413849.

Government of Pakistan (2018). Economic Survey, Economic Affairs Division, Govt. Pakistan, Islamabad.

Government of Pakistan (2019). Economic Survey of Pakistan. Finance Division, Economic Advisor's Wing, Islamabad, Pakistan.

Iqbal, T., M. T. Yousafzai., S. Ali, K. Sattar, M. Q. Saleem, U. Habib, and R. Khan (2018). There's No Such Thing as Free Lunch but Envy among Young Face bookers. KSII, TIIS, 12(10): 47244737.

ICSAG-Nigeria (Information and Communication Support for Agricultural Growth in Nigeria) (2005). Available at: www.ics-nigeria.info. Accessed on 8th Feb, 2014.

IFAD (The International Fund for Agricultural Development) (2012). Sustainable smallholder agriculture: Feeding the world, protecting the planet. IFAD, Rome, Italy. pp. 45.

Kamal, S., P. Amir and K. Mohtadullah (2012). Development of integrated river basin management for Indus Basin: Challenges and opportunities. Worldwide Funds for Nature Pakistan (Annual Report), Lahore, Pakistan. Available online at https://www.wwfpak.org/publication/pdf/irbm

Lemma, M. and B. Tesfaye (2016). From research 
extension linkages to innovation platforms: Formative history and evolution of multi stakeholder platforms in Ethiopia. J. Agric. Eco. Ext. and Rural. Develop. 4(7): 496-504.

Lipton, M. (2005). The Family Farm in a Globalizing World: The Role of Crop Science in Alleviating Poverty. 2020 Discussion Paper No. 40. Washington, DC: IFPRI Intl. Food. Policy Res Inst, pp. 29.

Mirani, Z. and A. Memon (2011). Farmer's assessment of the farm advisory services of public and private agricultural extension in Hyderabad district, Sindh. Pakistan J. Agric. Res. 24(1-4): 56-64.

Rahaman, M.M., O. Varis and T. Kajander (2007). EU Water Framework Directive vs. Integrated Water Resources Management: The Seven Mismatches, Int. J. Water Resource. D. 20(4): 565-575.

Rehman, Z.U., I.A. Wassan and M.K.B. Dost (2012). Socio-economic problems of farmers in Pakistan: Focused area Tauluka Pano Akil District Sukkur. Kuwait Chapter Arab. J. Business Manage. Rev. 1(5): 114-129.

Rathakrishnan, M and Q. Mahmood (2019). Agricultural issues and challenges in Pakistan: A content analysis approach, Multi. Discipl. J. of Instruct (MDJI) 1(2):1-13.

Sajjad, A., Y. Liu, A. Nazir, M. Ishaq, S. B. Khan, Abdullah and T. Shah (2020). Does technical progress mitigate climate effect on crops yield in Pakistan? The J. Anim. Plant Sci, 30(3): 663-676.

Sattar, M., M. Zafar, T. Mehmood, M. Ali and L. Khalid (2017). Economics of Growing Spring Maize in Cotton Wheat cropping pattern in Vehari Zone of
Punjab, Pakistan, Int. J. Adv. Multidisc. Res. 4(8):10-15.

Shah, T., J. Tao, F. Shah, A. Farooq, M. Ishaq and S. B. Khan (2016). A comparative study of the agricultural practices of members and nonmember farming community of Model farm Services Center in Khyber Pakhtunkhwa Pakistan, The J. Anim. Plant Sci, 26(6): 1787-1796

Shah, T., U. Hayat, M.S. Bacha and Muhammad (2019). An empirical analysis of livestock activities of the model farm service center in Khyber Pakhtunkhwa. Sarhad J. Agric, 35(2): 557-564.

Singh, J.P., B.E. Swanson and K.M. Singh (2006). Developing a decentralized, market-driven extension system in India: The ATMA model. Changing roles of agricultural extension in Asian nations, pp. 203-223.

Smith, L.D. (2004). Assessment of the Contribution of Irrigation to Poverty Reduction and Sustainable Livelihoods, Int. J. Water Res. D. 20(2): 243-257.

Vries, J.D. (2008). Goats for the poor: some keys to successful promotion of goat production among the poor. Small Ruminant Res, 77(2-3): 221-224.

Xie, H., L .You, B .Wielgosz and C. Ringler (2014). Estimating the Potential for Expanding Smallholder Irrigation in Sub-Saharan Africa. Agric. Water Manage, 131: 183-193.

Yousafzai, M.T., M. Nawaz, C. Xin, S.B. Tsai, and C.H. Lee (2020). Sustainability of waste picker sustainopreneurs in Pakistan's informal solid waste management system for cleaner production. J. Clean. Prod. 267(10): 121913. 